\title{
Neuropathologic findings of patients with COVID-19: a systematic review
}

\author{
Azalea T. Pajo ${ }^{1}$ (D) Adrian I. Espiritu ${ }^{1,2}$ (D) $\cdot$ Almira Doreen Abigail O. Apor ${ }^{1}$ (D) Roland Dominic G. Jamora $^{1,3}$ (D)
}

Received: 18 December 2020 / Accepted: 16 January 2021 / Published online: 22 January 2021

(C) Fondazione Società Italiana di Neurologia 2021

\begin{abstract}
Background Despite the expanding literature that discusses insights into the clinical picture and mechanisms by which the SARS-CoV-2 virus invades the nervous system, data on the neuropathologic findings of patients who died following SARS$\mathrm{CoV}-2$ infection is limited.

Methods A broad literature search was done for published articles that reported on histopathological findings of the brain in patients with COVID-19 in PubMed by MEDLINE, Embase, CENTRAL by the Cochrane Library, and SCOPUS from December 31, 2019 to October 31, 2020.

Results The systematic literature search strategy used resulted in a total of 1608 articles of which 14 were included in the analysis (PROSPERO registration number: CRD42020221022). There were ten case series, two case reports, one retrospective cohort, and one prospective cohort. The age of the patients ranged between 38 and 90 years old, most of them older than 65 years old $(n=66,45.2 \%)$ and males $(n=79,54.1 \%)$. Most tested negative in SARS-CoV-2 immunohistochemistry $(n=70,47.9 \%)$. The striking pathologic changes included diffuse edema $(n=25,17.1 \%)$, gliosis with diffuse activation of microglia and astrocytes $(n=52,35.6 \%)$, infarctions involving cortical and subcortical areas of the brain $(n=4,2.7 \%)$, intracranial bleed (subarachnoid hemorrhage and punctate hemorrhages) $(n=18,12.4 \%)$, arteriosclerosis $(n=43,29.5 \%)$, hypoxic-ischemic injury $(n=41,28.1 \%)$, and signs of inflammation $(n=52,35.6 \%)$. The cause of death was attributed to the cardiorespiratory system $(n=66,45.2 \%)$.

Conclusions The neuropathologic changes observed likely represent direct cytopathic effects and indirect effects secondary to host-specific inflammatory response induced by the viral infection. Further studies however are required to better elucidate the pathologic mechanism.
\end{abstract}

Keywords Neuropathology $\cdot$ COVID-19 $\cdot$ SARS-CoV-2

Roland Dominic G. Jamora

rgjamora@up.edu.ph

Azalea T. Pajo

atpajo@up.edu.ph

Adrian I. Espiritu

aiespiritu@up.edu.ph

Almira Doreen Abigail O. Apor

aoapor@up.edu.ph

1 Division of Adult Neurology, Department of Neurosciences, College of Medicine-Philippine General Hospital, University of the Philippines Manila, Manila, Philippines

2 Department of Clinical Epidemiology, College of Medicine, University of the Philippines Manila, Manila, Philippines

3 Section of Neurology, Institute for Neurosciences, St. Luke's Medical Center Global City, Taguig, Philippines

\section{Introduction}

In December 2019, a novel coronavirus emerged from Wuhan, Hubei Province, China, as the causing factor of pneumonia and severe acute respiratory syndrome [1]. Coronavirus disease 2019 (COVID-19) is caused by the severe acute respiratory syndrome coronavirus 2 (SARS-CoV-2) [2]. Although the involvement of the respiratory system is the most relevant clinical feature in COVID-19 patients, systematic reviews with meta-analysis demonstrate that the spectrum of clinical presentations is wider [3]. It has been reported that some severely affected patients experience neurological symptoms like headache, dizziness, and impaired sensorium while recent reports have noted that anosmia, ageusia, ataxia, and seizures may be early signs and symptoms in SARS-CoV-2-infected patients, suggesting that this virus may also be neurotropic [3-6]. In a recent study, it was found that 36.4\% COVID-19 
of patients presented with central nervous system (CNS) symptoms, $8.9 \%$ with peripheral nervous symptoms, and $10.7 \%$ with skeletal muscle symptoms [4].

The brain has been traditionally the target organ in several infectious diseases either by direct insult or as a secondary result of infection [1]. Coronaviruses (CoVs), specifically, have been known to exhibit neurotropic properties thereby causing neurologic sequelae [4]. SARS-CoV, for instance, which is $79.5 \%$ genetically similar to SARS-CoV-2, has been demonstrated in brain tissue from autopsies causing tissue edema and neuronal degeneration $[2,5]$. Two major pathways have been proposed for entry of neurotropic respiratory viruses into the CNS: the hematogenous and neuronal retrograde routes [7]. Despite the expanding literature that imparts insights into the clinical picture and mechanisms by which SARS-CoV-2 virus invades the nervous system, data on the neuropathologic findings of patients who died following SARS-CoV-2 infection is scarce. The aim of this paper was to review the currently available neuropathological data on COVID-19 including post-mortem findings of patients following a death from COVID-19 infection.

\section{Methods}

The Preferred Reporting Items for Systematic Reviews and Meta-Analyses (PRISMA) guidelines were followed for this study [8]. A broad literature search was performed to retrieve all relevant articles from December 31, 2019, to October 31, 2020. The protocol of this systematic review was registered in PROSPERO (registration number: CRD42020221022).

\section{Criteria for considering studies for review}

We considered case reports/series, cross-sectional, and cohort studies that reported on histopathological findings in the brain of patients with COVID-19. We also considered other article types such as letters to the editor and brief communications or correspondence. Preprint articles were included to increase the sample size. We did not apply any restrictions on age, sex, or ethnicity of patients in the studies. We excluded animal studies, unavailable full-text articles, and non-English articles. As the study was a systematic review of the literature, institutional ethical committee approval and informed consent were not obtained as we limited our study to published information.

\section{Search methods for identification and selection of studies}

Two investigators (ATP, AIE) performed an electronic search from December 31, 2019 up to October 31, 2020, using the following major healthcare databases: PubMed by MEDLINE, Embase, Scopus, CENTRAL by the Cochrane
Library, and medRxiv for preprint articles. We utilized the following comprehensive and MeSH terms: ("COVID" OR "Coronavirus" OR "COVID-19" OR "SARS-CoV-2" OR "nCoV disease") AND ("Neuropathology" OR "Neuropathologic findings" OR "neuropathologic" OR "neuropathological" OR "histopathological brain" OR "pathology brain" OR "histology" OR "autopsy"). We assessed the titles and abstracts using predefined screening criteria. Relevant articles were retrieved in full text and were subjected to predefined eligibility criteria. Three researchers (ATP, AIE, and RDGJ) independently examined the papers with titles or abstracts that appeared to be relevant and selected those that analyzed neuropathologic COVID-19 findings. The bibliographies of all identified relevant articles were examined and cross-referenced to further identify relevant literature to be included in this review. Studies that satisfied these criteria were included in the analysis. Disagreements concerning eligibility among the researchers were resolved by consensus.

\section{Methodological assessment of included studies}

The methodological quality of the included studies was evaluated by two investigators (ATP, AIE) studies using the Murad tool for non-comparative cohorts and case reports/series [9]. Comparative cohorts and cross-sectional studies were evaluated using the Newcastle-Ottawa Scale in terms of selection, comparability, and outcome domains [10]. We considered "poor," "moderate," or "good" quality when 3 or fewer, 4 , or 5 of the criteria were fulfilled in the Murad tool, and 3 points or fewer, 4-5, or 6 and above in the Newcastle-Ottawa Scale. Any disagreement was resolved by consensus with one more investigator (ADAOA).

\section{Data collection and analysis}

We extracted data from the full text of the articles using a predefined data extraction form. The following information was obtained from each included study: author and year, publication date, study design, study duration, setting, number of included patients, age/age range, sex, descriptive neuropathologic findings or histopathological findings of the brain, and other relevant clinical information of patients (COVID testing, comorbidities, duration of disease, and cause of death). Categorical variables were pooled as frequencies and percentages while continuous variables were summarized using means or medians with standard deviation or ranges.

\section{Results}

\section{Included studies}

The systematic literature search strategy used with a date filter between December 31, 2019 and October 31, 2020, resulted in 
a total of 1629 articles. After deduplication, 1065 articles were screened based on their abstract. We excluded 1041 articles that were unrelated to the neuropathological findings in patients with COVID-19. This evaluation left 24 articles, only 14 of which met the eligibility criteria for synthesis in this review. There were ten case series [11-20], two case reports [21, 22], one retrospective cohort [23], and one prospective cohort [24]. Figure 1 illustrates our search strategy.

The characteristics of the scientific papers and their quality assessment are presented in Supplemental Table 1. The included studies originated mostly from the USA while others were performed in the UK, Switzerland, Germany, Finland, Italy, and the Netherlands. Sample size ranged from 1 to 50 with varying study duration ranging from 1 to 3 months.

\section{Population characteristics}

Out of the total 165 cases in the literature included in this review, only 146 patients were included in the synthesis; 19 of these cases did not undergo a pathological study of the brain and were excluded in the final analysis [14, 24]. The demographic data are summarized in Table 1. The age of the patients ranged from 38 to 90 years old; however, most of them fall under those older than 65 years old $(n=66,45.2 \%)$. Majority were males $(n=79,54.1 \%)$, and $26.7 \%$ were females $(n=39)$, while the rest was unreported $(n=28,19.2 \%)$. A significant number of cases had relevant pre-existing medical conditions, mainly cardiovascular $(n=114,78.1 \%)$, respiratory $(n=31,21.2 \%)$, diabetes mellitus (DM) $(n=22,15.1 \%)$, and renal diseases $(n=22,15.1 \%)$. A few had neurologic comorbidity such as a history of stroke and epilepsy ( $n=11,7.5 \%)$, while the rest had metabolic conditions namely gout $(n=1$, $0.7 \%)$, dyslipidemia $(n=8,5.5 \%)$, and obesity $(n=13,8.9 \%)$. A few of these patients had a history of smoking $(n=3,2.1 \%)$. Other findings include malignancies (solid or hematologic) $(n=15,10.3 \%)$. The limited available data on presenting neurologic symptoms revealed that altered mental status was the most common symptom $(n=14,43.8 \%)$ followed by delirium $(n=9,28.1 \%)$ [12, 14, 15, 19, 21, 23, 24]. Less common encountered presentations included cranial nerve pathologies signifying a cerebrovascular event $(n=2,6.3 \%)$, headache, nausea and vomiting, aphasia, and ageusia $(n=1,3.1 \%)$ while the rest remained unreported $(n=114,78.1 \%)$. The duration of hospital illness was unreported in most of the cases $(n=62$, $42.5 \%$ ); however, for the remaining number of patients, most were cared for more than 10 days in different medical institutions $(n=44,30.1 \%)$. The majority died during the confinement period ( $n=145,99.3 \%$ ) while the rest of the patients $(n=1,0.7 \%)$ remained under intensive care thereafter. The cause of death was mainly attributed to the cardiorespiratory
Fig. 1 PRISMA flow diagram for study selection

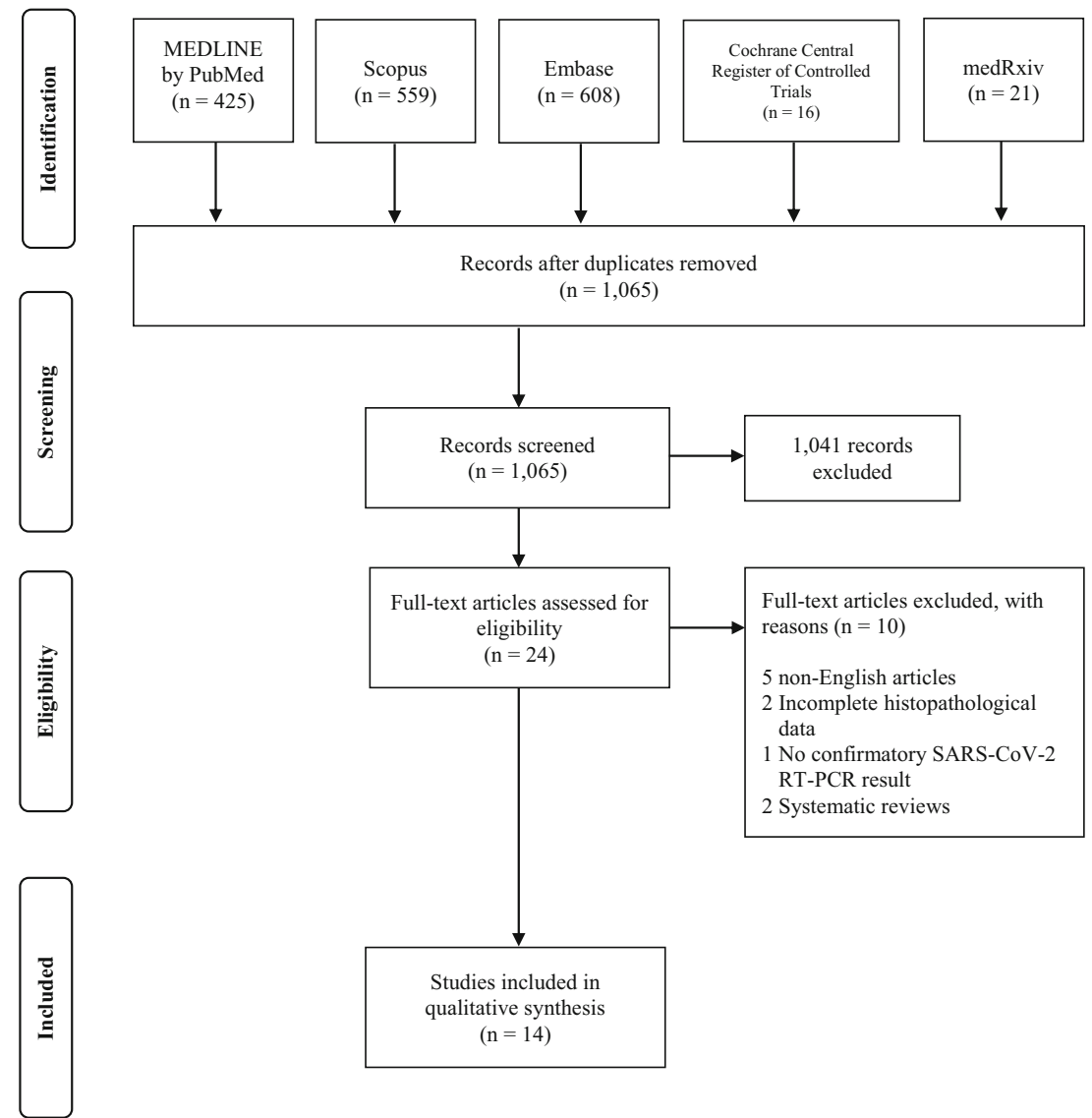


Table 1 Characteristics of the included studies and population, and quality assessment

\begin{tabular}{|c|c|c|c|c|c|c|c|}
\hline Author & Setting & $\begin{array}{l}\text { Sample } \\
(n)\end{array}$ & Study design & Study duration & $\begin{array}{l}\text { Age/age range } \\
\text { (mean) }\end{array}$ & $\begin{array}{l}\text { Sex } \\
(F: M)\end{array}$ & $\begin{array}{l}\text { Quality } \\
\text { assessment }\end{array}$ \\
\hline Younger, 2020 & USA & 50 & Case series & NI & NI & NI & Good \\
\hline Keller et al., 2020 & Switzerland & $8^{+}$ & Case series & March 9 to April 3, 2020 & $(67.6)$ & $1: 7$ & Good \\
\hline Matschke et al., 2020 & Germany & 43 & Case series & March 13-April 24, 2020 & $51-94$ & $16: 27$ & Good \\
\hline Jensen et al., 2020 & UK & 2 & Case series & NI & $66-71$ & $0: 2$ & Good \\
\hline Kantonen et al., 2020 & Finland & 4 & Case series & April 14-May 18, 2020 & $38-90$ & $1: 3$ & Good \\
\hline Conklin et al., 2020 & USA & 1 & $\begin{array}{l}\text { Retrospective } \\
\text { cohort }\end{array}$ & March 12-May 14, 2020 & 57 & $0: 1$ & Good \\
\hline Reichard et al., 2020 & USA & 1 & Case report & NI & 71 & NI & Good \\
\hline Patel et al., 2020 & USA & 1 & Case report & NI & 48 & NI & Good \\
\hline Fabbri et al., 2020 & Italy & 10 & Case series & NI & $51-74$ & $3: 7$ & Good \\
\hline Barton et al., 2020 & USA & 2 & Case series & March 1-31, 2020 & 42,77 & $0: 2$ & Good \\
\hline $\begin{array}{l}\text { von Weyhern et al., } \\
2020\end{array}$ & Germany & 6 & Case series & April 1-30, 2020 & $58-82$ & $1: 2$ & Good \\
\hline Bradley et al., 2020 & USA & 14 & Case series & February-March 2020 & $42-84$ & $4: 3$ & Good \\
\hline $\begin{array}{l}\text { Jaunmuktane et al., } \\
2020\end{array}$ & UK & 2 & Case series & NI & $50-60$ & $1: 1$ & Good \\
\hline Schurink et al., 2020 & Netherlands & $21 \dagger$ & Prospective cohort & $\begin{array}{l}\text { March } 9 \text { and May } 18, \\
2020\end{array}$ & $41-78$ & $5: 16$ & Good \\
\hline
\end{tabular}

$N$, not indicated

${ }^{\dagger}$ Only 9 patients consented to autopsy

${ }^{+}$Only 1 patient consented to autopsy

system, with viral pneumonia as the underlying condition in most cases $(n=66,45.2 \%)$; however, the cause of death was not reported in $33.6 \%$ ( $n=49)$ (Table 2).

\section{Neuropathologic findings in patients with COVID-19}

\section{SARS-CoV-2 reactivity in brain sections}

A subset of cases $(n=146)$ diagnosed with SARS-CoV-2 infection underwent biopsy or post-mortem examination for pathologic study of the brain [11-13, 15-23]. SARS-CoV-2 reactivity in brain sections of these patients was positive in only $15.1 \%(n=22)[13,18]$. Most patients tested negative in SARS-CoV-2 immunohistochemistry $(n=70,47.9 \%)[11,13$, $15,16,18,24]$, while the rest was unreported $(n=54,37 \%)$ $[11,12,14,17,19-23]$. No pathologic findings concerning the peripheral nervous system (PNS) were reported.

\section{Macroscopic and histopathologic findings}

The mean unfixed brain weight was $1378.2 \mathrm{~kg}[13,18-20$, 23]. All 146 decedents examined by gross standard autopsy showed absence of gross abnormalities in $10.3 \%(n=15)$ [16, $19,20,24]$ while diffuse brain edema commonly seen as nonspecific axonal changes was observed in $17.1 \%(n=25)$ [ 13 , $22,23]$. Four brains $(2.7 \%)$ exhibited glial scars representing chronic infarcts $[15,16,18]$. These infarctions were demonstrated in the cortical and deep-seated areas like the basal ganglia and the brainstem, and even in watershed areas. There was evidence of intracranial bleeding localized in the cerebellum $(n=3,2.1 \%)[14,16]$. Uncal and tonsillar herniation was seen in one patient $(0.7 \%)$ [23]. Other gross findings were varying degrees of atherosclerotic disease $(n=43,29.5 \%)$ (Fig. 2) [13].

In a significant number of analyzed patients, various stages of gliosis were observed with diffuse microglial activation and reactive gliosis documented in $35.6 \%(n=52)$ of patients [13, $17,18,22,24]$. Diffuse activation of the microglia and astrocytes were pronounced in the brainstem and the cerebellum. Histopathological examination of specimens further demonstrated hypoxic changes $(n=41,28.1 \%)[11,15,18,22,23]$ with evidence of leptomeningeal inflammation $(n=7,4.8 \%)$ [11]. These hypoxic changes were seen in the hippocampus (CA1 region), parahippocampus, cerebellar Purkinje cells, neocortex, brainstem nuclei, olfactory bulb, chiasma, neostriatum, and spinal cord.

Microscopic evaluation further exhibited cellular components signifying distinct stages into the inflammatory process as demonstrated by the presence of cerebral venous neutrophilic infiltrates $(n=2,1.4 \%)[21,22]$, perivascular lymphocytic infiltrates $(n=50,34.2)[11,13,16,22,24]$, perivascular degeneration and calcification $(n=5,3.4 \%)[15,16]$, and 
Table 2 Clinical and pathologic characteristics of cases

\begin{tabular}{|c|c|c|}
\hline Observation & $\begin{array}{l}\text { Number of cases } \\
(N=146)\end{array}$ & $\%$ \\
\hline \multicolumn{3}{|l|}{ Sex } \\
\hline Male & 79 & 54.1 \\
\hline Female & 39 & 26.7 \\
\hline Not reported & 28 & 19.2 \\
\hline \multicolumn{3}{|l|}{ Age } \\
\hline$<21$ & 0 & 0.0 \\
\hline $21-49$ & 6 & 4.1 \\
\hline $50-64$ & 27 & 18.5 \\
\hline$>65$ & 66 & 45.2 \\
\hline Not reported & 47 & 32.2 \\
\hline \multicolumn{3}{|l|}{ Duration of hospital illness } \\
\hline $0-1$ & 9 & 6.2 \\
\hline $1-10$ & 31 & 21.2 \\
\hline$>10$ & 44 & 30.1 \\
\hline Not reported & 62 & 42.5 \\
\hline \multicolumn{3}{|l|}{ Neurologic symptoms } \\
\hline Not reported & 114 & 78.1 \\
\hline No neurological symptoms & 3 & 9.4 \\
\hline Headache & 1 & 3.1 \\
\hline Delirium & 9 & 28.1 \\
\hline Nausea and vomiting & 1 & 3.1 \\
\hline Altered mental status & 14 & 43.8 \\
\hline Craniopathies & 2 & 6.3 \\
\hline Aphasia & 1 & 3.1 \\
\hline Ageusia & 1 & 3.1 \\
\hline \multicolumn{3}{|l|}{ SARS-Cov-2 reactivity in brain sections } \\
\hline Positive & 22 & 15.1 \\
\hline Negative & 70 & 47.9 \\
\hline Not reported & 54 & 37.0 \\
\hline \multicolumn{3}{|l|}{ Neuropathology } \\
\hline No gross abnormalities & 15 & 10.3 \\
\hline Global hypoxic-ischemic injury & 41 & 28.1 \\
\hline $\begin{array}{l}\text { Small-vessel ectasia with variable } \\
\text { perivascular } \\
\text { edema and perivascular } \\
\text { microhemorrhages }\end{array}$ & 10 & 6.8 \\
\hline Perivascular degeneration & 4 & 2.7 \\
\hline Perivascular calcification & 1 & 0.7 \\
\hline Leptomeningeal inflammation & 7 & 4.8 \\
\hline Perivascular infiltrates/lymphocytic & 50 & 34.2 \\
\hline Endovascular microthrombi & 10 & 6.8 \\
\hline Microglial activation/reactive gliosis & 52 & 35.6 \\
\hline Glial scar/chronic infarcts & 4 & 2.7 \\
\hline Recent microscopic cortical infarcts & 24 & 16.4 \\
\hline Cerebral venous neutrophilic infiltration & 2 & 1.4 \\
\hline Diffuse brain edema & 25 & 17.1 \\
\hline Uncal and tonsillar herniation & 1 & 0.7 \\
\hline Acute microscopic/punctate hemorrhages & 15 & 10.3 \\
\hline Neuronal cell loss & 6 & 4.1 \\
\hline Axonal degeneration/injury & 4 & 2.7 \\
\hline Arteriosclerosis & 43 & 29.5 \\
\hline
\end{tabular}

variable degrees of neuronal cell loss and axonal degeneration/injury $(n=10,6.8 \%)[11,12,22]$. Other findings included small-vessel ectasia with variable perivascular edema and perivascular microhemorrhages $(n=10,6.8 \%)$ [18], endovascular microthrombi $(n=10,6.8 \%)$ [18], recent microscopic cortical infarcts $(n=24,16.4 \%)[11,13,14,16-18,22]$, and acute microscopic/punctate hemorrhages $(n=15,10.3 \%)$ $[11,12,14,17,19,22,23]$.

\section{Discussion}

Recent evidence suggests that COVID-19 involve the CNS and PNS after increasing clinical reports of symptoms suggesting CNS affectation such as headache, impaired consciousness, and acute cerebrovascular diseases [25]. Whether these neurologic manifestations resulted from direct viral invasion or indirect mechanisms that have yet to be elucidated, it is essential to establish the pathologic mechanism of the neurotrophic properties of COVID-19. Thus far, published data on the neuropathological changes associated with COVID-19 have been scarce and controversial, and neuropathological descriptions have ranged from only modest or no pathology to severe hemorrhagic and hypoxic phenotypes, thrombotic complications, acute disseminated encephalomyelitis (ADEM)-like changes, and encephalitis and meningitis [12, $15,22,26,27]$. As a result, studies on the spectrum of neuropathological findings in patients who died of COVID-19 is now starting to emerge as these pathologic changes likely represent the direct and indirect effects of COVID-19 infection.

The striking pathologic changes presented in this paper include findings of (a) diffuse edema, (b) gliosis with diffuse activation of microglia and astrocytes, (c) infarctions involving cortical and subcortical areas of the brain, (d) intracranial bleed (e.g., subarachnoid hemorrhage (SAH) and punctate hemorrhages), (e) varying degrees of arteriosclerosis, (f) evidence of hypoxic-ischemic injury, (g) differing stages of inflammation as demonstrated by the presence of cellular components infiltrating into perivascular areas of the brain, (h) presence of endovascular microthrombi, and (i) variable degrees of neuronal cell loss and axonal degeneration/injury. Moreover, SARS-CoV-2 reactivity in brain tissue has been demonstrated in a proportion of the cases.

\section{Direct and indirect effects on the central nervous system}

In terms of CNS involvement, several cases presented with varying degrees of diffuse edema of the brain surface showing widened gyri, flattened surface, narrowed sulci, and meningeal congestion with diffuse discoloration of the gray-white matter junction. In addition, some of these revealed foci of intraparenchymal blood that disrupted the white matter, with macrophages at the periphery of the lesions on routine hematoxylin and eosinophilic histological examination. Findings of brain swelling were not uncommon in patients affected with COVID-19 even in the pediatric population [28]. However, in contrast to the mechanism of injury in lung involvement in 


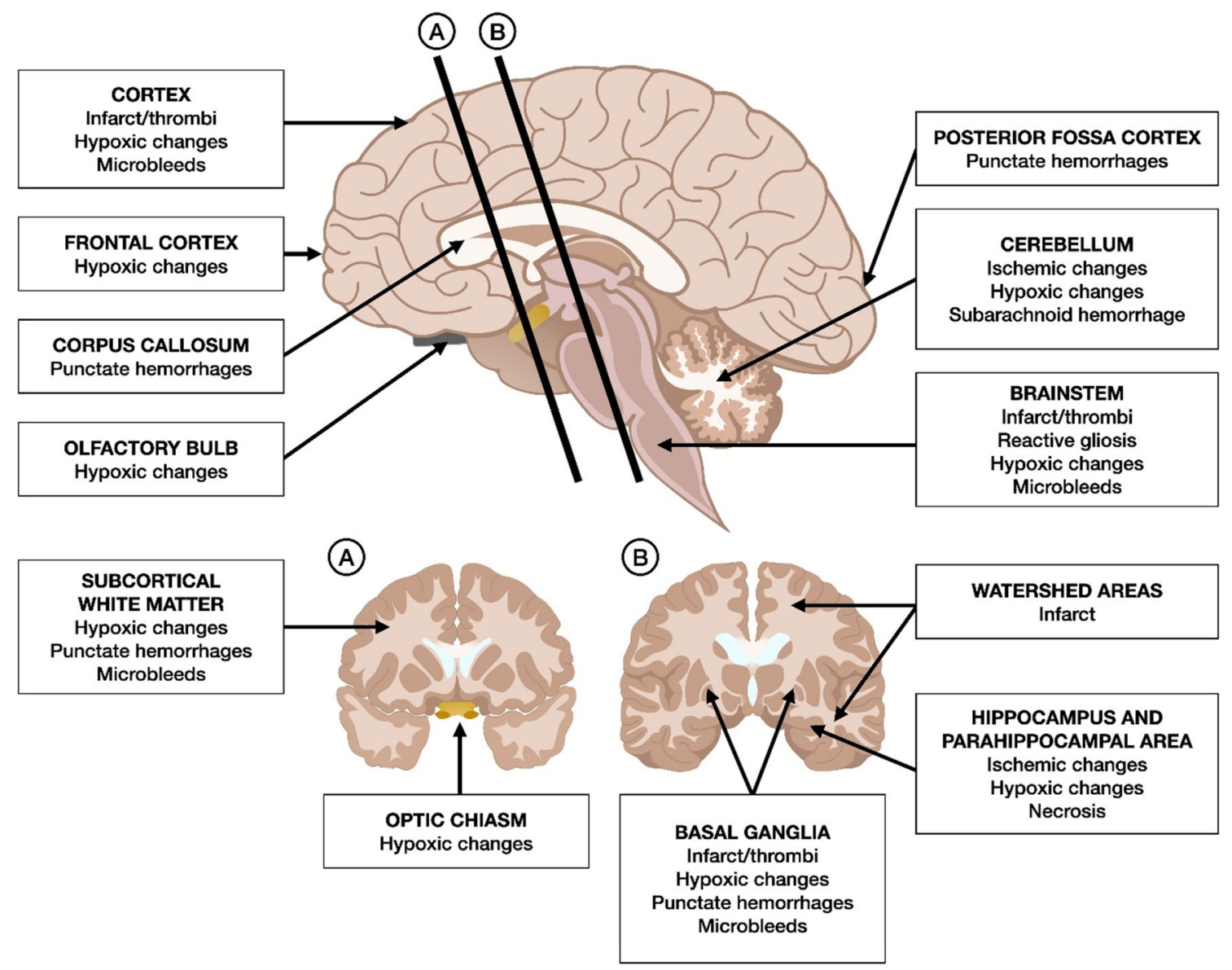

Fig. 2 Neuropathologic findings in patients with SARS-CoV-2 infection. At the level of the optic chiasm (A), there was a note of hypoxic changes, while at the level of the basal ganglia (B), prominent changes include watershed infarctions, hypoxic changes, punctate hemorrhages, and microbleeds. There was also a note of hypoxic and ischemic changes in the hippocampus, others with evidence of necrosis. Other pathologic changes observed include diffuse cerebral edema, gliosis with diffuse activation of microglia and astrocytes, infarctions involving cortical and

COVID-19, the pathologic mechanism of brain swelling in these patients remained to be determined as either a result of direct invasion or a consequence of host-specific inflammatory response as supported by the presence of macrophages and other inflammatory cellular components surrounding these tissues $[29,30]$. The complexity of the underlying pathophysiological mechanism of post-viral olfactory dysfunction as the route of entry causing direct neural invasion must still be established in the case of SARS-CoV-2 infection.

Macroscopic examination of some of these brain specimens also revealed a focus of extravasated blood mostly seen over the cerebellar hemisphere, consistent with a small SAH. These findings supported the previously reported predisposition of COVID-19 patients to the development of intracranial hemorrhage (ICH) during critical illness [31, 32]. The pathophysiology is unclear, but the tropism of SARS-CoV-2 to the endothelial lining of the cerebral vasculature via their angiotensin-converting enzyme (ACE) II receptors may

subcortical areas of the brain, intracranial bleed (e.g., subarachnoid hemorrhage (SAH) and punctate hemorrhages), varying degrees of arteriosclerosis, evidence of hypoxic-ischemic injury, differing stages of inflammation as demonstrated by the presence of cellular components infiltrating into perivascular areas of the brain, presence of endovascular microthrombi, variable degrees of neuronal cell loss, and axonal degeneration/injury

provide an explanation. A recent pathologic study demonstrated the presence of virus particles within endothelial cells and an accumulation of inflammatory cells, leading to endothelial cell death [31]. Angiotensin II receptors, being expressed in circumventricular organs and in cerebrovascular endothelial cells, play a role in the regulation of multiple functions in the brain, including regulation of hormone formation and sympathoadrenal system, water and sodium intake, vascular autoregulation, and cerebral blood flow, and with dysfunction, it may lead to the disruption of autoregulation as well as blood pressure spikes due to arterial wall rupture [33]. However, this should not be interpreted independently from the cardiovascular risk factors which pose further risk towards ICH development. Among the associated risk factors were older age and respiratory failure. In addition, the use of anticoagulation was associated with a fivefold risk of ICH [34].

Encephalitis is the inflammation of the brain parenchyma, usually caused by an infection or the body's immune defenses 
[35]. Although it is strictly speaking a pathological diagnosis, for practical purposes, clinical evidence of brain inflammation is accepted, such as a CSF pleocytosis, imaging changes, or focal abnormalities on electroencephalography [35]. The World Health Organization (WHO) COVID-19 case definition of possible SARS-CoV-2 meningitis, encephalitis, myelitis, or CNS vasculitis is as follows: patient meets suspected case definition of COVID-19 according to national or WHO guidance on the basis of clinical symptoms and epidemiological risk factors; in the context of known community SARSCoV-2 transmission, supportive features include the following: the new onset of at least one of cough, fever, muscle aches, loss of smell, or loss of taste; lymphopenia or raised D-dimer level, and radiological evidence of abnormalities consistent with infection or inflammation (e.g., ground glass changes) [35]. In this review, histopathological studies of several brain specimens showed focal or diffuse cortical, brainstem, or leptomeningeal inflammation, characterized as T cell-mediated based upon flow cytometry as well as histopathological features of encephalitis including localized perivascular and interstitial infiltrates with neuronal cell loss and axonal degeneration involving brainstem nuclei and tracts without territorial infarctions, or evidence of virus infiltration $[11,17]$. The first case of meningitis associated with SARS$\mathrm{CoV}-2$ was published in May 2020 presenting as convulsion and unconsciousness with brain imaging showing hyperintensity along the wall of the right lateral ventricle and hyperintense signal changes in the right mesial temporal lobe and hippocampus [36]. Months into the pandemic, case reports of patients presenting as an encephalitis syndrome of drowsiness, mental disorientation, intermittent fever, and headache with imaging findings consistent with encephalitis emerged [37-39]. In a nationwide surveillance study to investigate the spectrum of neurological and psychiatric complications of COVID-19 across the UK, altered mental status including encephalopathy or encephalitis and primary psychiatric diagnoses was the second most common neuropsychiatric complication, often occurring in younger patients [40]. The exact pathogenic mechanism involved in neurologic injury in these cases is difficult to ascertain; however, given the constellation of pathologic findings described in the cases presented in this review and the neurologic presentation of these patients, both direct viral infection and host-specific inflammatory response might be pointed as the cause as supported also by post-mortem studies in different cases of SARS-CoV2 infection [38, 41-43].

Intravascular microthrombi and multiple infarcts (either focal microscopic or deep-seated, i.e., located in the basal ganglia and through the brainstem) seen in some of the cases were consistent with the pro-coagulant state of SARS-CoV-2infected patients leading to an increased risk to thrombotic events and hemorrhagic parenchymal tissue infarction from large- and small-vessel thrombosis [11, 18]. An association between COVID-19 and strokes has been described with characteristics including large-vessel occlusion, multi-territory infarcts, concomitant venous thromboembolism, raised inflammatory markers, antiphospholipid antibody production, younger age of stroke, premorbid vascular comorbidities, and a higher incidence of stroke with increasing COVID-19 severity [44-46]. Additionally, viral components specifically in the endothelial cells have been documented in the brain in addition to viral RNA detected in the cerebrospinal fluid (CSF) and this may be contributory to the pathologic pro-thrombotic state $[17,31]$. This was in keeping with the role of the vascular endothelium that is indispensable in regulating the vascular tone and the maintenance of vascular homeostasis [31, 32]. Endothelial dysfunction is a principal determinant in microvascular dysfunction which shifts equilibrium favoring vasoconstriction and a pro-coagulant state [32]. However, these findings should be interpreted with caution given the presence of competing premorbid vascular risk factors in these patients which could have accentuated their risk for pro-thrombotic events. Conversely, ischemic lesions in watershed zones may represent areas of hypoperfusion with hemodynamic instability especially observed in patients with renal failure and sepsis [47].

The presence of ischemic red neurons and pyknotic and eosinophilic neurons in hypoxia-sensitive areas (hippocampus (CA1 region), parahippocampus, cerebellar Purkinje cells, neocortex, brainstem nuclei, olfactory bulb, chiasma, neostriatum, and even the spinal cord was consistent with the global hypoxic injury $[15,18]$. Furthermore, the presence of diffuse microvascular injury (microhemorrhages and microscopic ischemic lesions) involving the subcortical and deep white matter in some of the specimens correlates to the deleterious effects caused by hypoxia. These findings perplexed physicians as to direct causality or secondary effect as complications following ventilation assistance, sedation, or hypoxia with hypoperfusion $[48,49]$. The neuroanatomic distribution of the microvascular lesions as observed in these cases, particularly the callosal and capsular predominance, has been reported as a rare complication of acute respiratory distress syndrome (ARDS), high altitude exposure, and extracorporeal membrane oxygenation (ECMO), all of which are associated with cerebral hypoxia [23]. Further adding to the insult, ARDS is a major complication in severe COVID-19 pneumonia that necessitates respiratory support, with high percentage of invasive ventilation [48]. This in turn requires high demand for other several therapies including sedatives and paralytics [48]. In many cases, sedation can be prolonged resulting in an increase in the prevalence of ventilation-associated hypoxia which further aggravates the condition of these patients [48-51]. Of note was the detection of microthrombi and ischemic damage, reactive gliosis, and microglial activation in the brainstem which could serve as the driving mechanism towards consequent brainstem damage appearing as the 
terminal event [18]. This may manifest through the phenomenon of prolonged unresponsiveness after extubation following long-term ventilatory support in COVID-19 patients. As such, the use of cerebral hypoxymetry that measures oxyhemoglobin saturation has been explored as an "early warning indicator" of the decreased brain oxygen delivery which can be utilized to optimize cerebral oxygen supply and demand, inversing the decreased cerebral perfusion and/or preventing protracted brain ischemia [52]. However, data in this respect is still limited.

Finally, an explanation on the inconsistent demonstration of the virus in the CSF has been put forward in a recently published study. It could be that the virus is mainly cellbound and spread from cell to cell without entering the CSF. Second, the virus might have been present in the CSF at concentrations below the level of detection of the testing method because of a delay in CSF sampling. Third, the presence of heme products resulting from the breakdown of erythrocytes in the CSF could inhibit the action of the polymerase and, thus, the detection of SARS-CoV-2. Alternatively, the failure to detect SARS-CoV-2 in CSF despite evidence of inflammation raises the possibility that in some individuals, COVID19-related encephalitis might result from immune-mediated inflammatory mechanisms, in the absence of direct virus invasion [53].

\section{Possible mechanisms underlying SARS-CoV-2- mediated neurological injury}

Pooling all the neuropathological findings from patients with COVID-19 provides insight as to the mechanism employed by SARS-CoV-2 to infect the nervous system. The pathological features of COVID-19 greatly resemble those seen on SARS and Middle East respiratory syndrome (MERS) coronavirus infection [25]. Therefore, previous observations regarding routes of viral entry and propagation made on the aforementioned coronaviruses can be hypothesized here as well [54].

There are three proposed routes by which SARS-CoV-2 gain access into the brain: (a) through breach in the bloodbrain barrier (BBB), (b) through retrograde axonal transport/ trans-neuronal transport, and lastly (c) through the vagus nerve (Fig. 3) [54]. The initial step of SARS-CoV-2 infection is the receptor recognition on the surface of the host cells [53-55]. Similar to SARS-CoV-1, this step is mediated by the viral spike (S) protein, which utilizes the human receptor angiotensin I-converting enzyme 2 (ACE2) as the docking receptor [53-55]. Hence, organ distribution of the ACE2 receptor is crucial in the inciting event in the pathogenesis of SARS-CoV-2 infection. ACE2 is widely expressed in the airway epithelium, lung parenchyma, vasculature, kidney, heart, and gastrointestinal tract [53-57]. Recent reports indicate that ACE2 is also expressed in neurons, astrocytes, and oligodendrocytes, as well as in the substantia nigra, ventricles, middle temporal gyrus, posterior cingulate cortex, and olfactory bulb [53]. Additionally, it has been determined that tissue patterns of expression of transmembrane serine protease (TMPRSS2 and TMPRSS4), and cathepsin L is another decisive factor that determines the tropism of the virus [54]. TMPRSS4 can be demonstrated in the cerebral cortex, hippocampus, caudate, thyroid gland, adrenal gland, nasopharynx, bronchi, lung, stomach, duodenum, colon, rectum, gallbladder, pancreas, and genitourinary tract [54].

In COVID-19, dissemination of the virus into the blood has been described in $1-41 \%$ of patients [55]. A breach in the BBB where there is high expression of ACE2 receptors provides the mechanism for the hematogenous route of viral invasion [5, 31, 33, 54]. After infecting the airways, coronaviruses can, under certain circumstances, pass through the epithelial barrier, gain access to the bloodstream, and then enter the CNS by either infecting endothelial cells of the BBB or epithelial cells of the blood-CSF barrier in the choroid plexus. Furthermore, evidence suggests that coronaviruses can infect leukocytes. Once activated by infection, these leukocytes disseminate towards other tissues and cross the BBB to access the CNS [53]. The infection of endothelial cells causes rupture of the capillaries leading to ICH or hemorrhagic infarction and other forms of endothelial damage as demonstrated in this review [25]. However, direct evidence in cerebral endothelial cells has not been thus far provided [55]. Further confounding this theory is the implicated effect of high concentrations of pro-inflammatory cytokines in the systemic circulation of patients with severe forms of COVID19 which induces structural and functional alterations of the BBB [54].

Retrograde viral dissemination, on the other hand, is a process wherein a virus infects neurons in the periphery uses the transport machinery within those cells to gain access to the CNS [53]. In this sense, the virus could penetrate the CNS through the neuroepithelium of the olfactory mucosa to reach the olfactory bulb, gain access to the mitral cells and the olfactory nerve, and then spread to adjacent areas of the brain such as the hippocampus and other brain structures [53, 54]. This route was demonstrated in mice with intracranially inoculated SARS-CoV-1 and was supported by anosmia as one of the early symptoms in COVID-19 infection [3, 5, 54]. As previously mentioned, ACE2 and TMPRSS2 have been detected in the nasal mucosa; however, reports demonstrated that they are rather localized to epithelial cells (sustentacular cells) and not in the olfactory neurons [55]. Therefore, it is still unclear whether the virus is restricted to the olfactory epithelium or reaches olfactory neurons through endocytosis and retrograde transport.

A third possible route of entry into the CNS is via the immune cells which also serves as a reservoir [25, 55]. The virus enters the body through the respiratory tract and first infects the epithelial cells of the trachea and bronchi and the 
alveolar cells of the lung, subsequently infecting the resident immune cells which transport the virus to other organs, including the brain [25]. However, conclusive evidence of SARSCoV-2 infectivity in immune cells has not been provided at this point.

Finally, as in the case of other respiratory viruses with neurotropic potential as in the case of the influenza A virus, SARS-CoV-2 could gain entry to the CNS by means of the vagus nerve through its terminals located along the respiratory and gastrointestinal tract. These sites have high expression of ACE2 and enriched ACE2+TMPRSS2+enteric neurons. From this vantage point, the virus could gain entry to the brain stem, taking advantage of the polarization of neurons and the machinery responsible for retrograde neuronal communication, or through endocytosis and clathrin-mediated exocytosis [54].

Our main limitation in this study was the descriptive nature of the review. The literature search method may have also limited the number of outcomes from failure of inclusion of non-indexed papers which could have contributed to the data. Second, the lack of age- and sex-matched controls in the cases presented in the articles included in the synthesis which could have better delineate the differences in the gross and histopathologic studies of the brain in these two arms. Furthermore, some of the articles included in the synthesis failed to provide the neurologic signs and symptoms of the patients which is important in the interpretation of findings as to the nature of the neurologic involvement. Lastly, certain external factors like sample preservation and the different protocols used in the autopsy could have affected the condition of the specimens.

\section{Conclusion}

Our understanding of the neuropathology of SARS-CoV-2 infection continues to evolve. In this review, we described the varying neuropathologic findings seen in COVID-19infected patients. The pathologic changes observed in the brain likely represent the direct cytopathic effects mediated by SARS-CoV-2 infection and the indirect effects secondary to host-specific inflammatory response induced by the viral

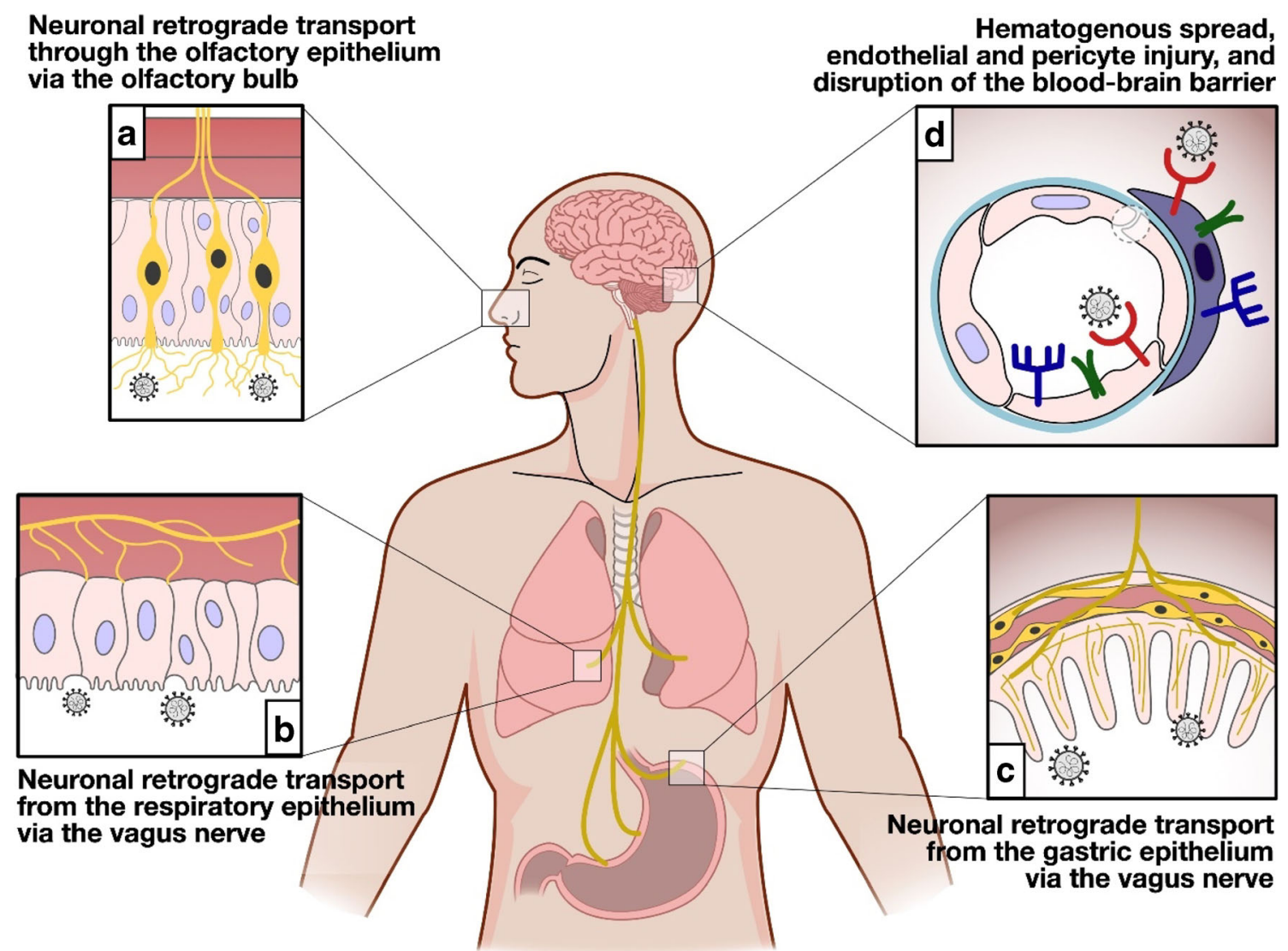

Fig. 3 Possible mechanisms underlying SARS-CoV-2-mediated neurological injury. SARS-CoV-2 can possibly gain access to the brain following three routes. (A) The virus could penetrate the CNS through the neuroepithelium of the olfactory mucosa to reach the olfactory bulb, gain access to the mitral cells and the olfactory nerve, and then spread to adjacent areas of the brain such as the hippocampus and other brain structures through retrograde viral transmission. (B and C) SARS-CoV2 could also gain entry to the CNS by means of the vagus nerve through its terminals located along the respiratory and gastrointestinal tract. (D) Breach in the BBB where there is high expression of ACE2 receptors provides the mechanism for the hematogenous route of viral invasion 
infection. Further studies are needed to better elucidate the pathologic mechanism resulting in the neurologic involvement in patients with COVID-19 infection.

Supplementary Information The online version contains supplementary material available at https://doi.org/10.1007/s10072-021-05068-7.

Materials availability The datasets used and/or analyzed during the current study are available from the corresponding author on reasonable request.

Author contribution ATP: conceptualization, data curation, formal analysis, interpretation of data, writing-original draft, writing-review, and editing. AIE: conceptualization, data curation, formal analysis, interpretation of data, writing-original draft, writing-review, and editing. ADAOA: conceptualization, data curation, formal analysis, interpretation of data, writing-original draft, writing-review, and editing. RDGJ: conceptualization, data curation, formal analysis, interpretation of data, writing-original draft, writing-review, and editing. All authors have read and approved the final manuscript.

Data availability The datasets used and/or analyzed during the current study are available from the corresponding author on reasonable request.

\section{Declarations}

Ethics approval and consent to participate Not applicable.

Consent for publication Not applicable.

Competing interests The authors declare no competing interests.

\section{References}

1. Tsivgoulis G, Palaiodimou L, Katsanos AH, Caso V, Köhrmann M, Molina C, Cordonnier C, Fischer U, Kelly P, Sharma VK, Chan AC, Zand R, Sarraj A, Schellinger PD, Voumvourakis KI, Grigoriadis N, Alexandrov AV, Tsiodras S (2020) Neurological manifestations and implications of COVID-19 pandemic. Ther Adv Neurol Disord. 13:175628642093203. https://doi.org/10. $1177 / 1756286420932036$

2. Wu Y, Xu X, Chen Z, Duan J, Hashimoto K, Yang L, Liu C, Yang C (2020) Nervous system involvement after infection with COVID19 and other coronaviruses. Brain Behav Immun 87:18-22. https:// doi.org/10.1016/j.bbi.2020.03.031

3. Franca RA, Ugga L, Guadagno E, Russo D, Del Basso De Caro M (2020) Neuroinvasive potential of SARS-CoV2 with neuroradiological and neuropathological findings: is the brain a target or a victim? APMIS. 129:37-54. https://doi.org/10.1111/apm.13092

4. Collantes MEV, Espiritu AI, Sy MCC, Anlacan VMM, Jamora RDG (2021) Neurological manifestations in COVID-19 infection: a systematic review and meta-analysis. Can J Neurol Sci 48:66-76. https://doi.org/10.1017/cjn.2020.146

5. Paniz-Mondolfi A, Bryce C, Grimes Z, Gordon RE, Reidy J, Lednicky J, Sordillo EM, Fowkes M (2020) Central nervous system involvement by severe acute respiratory syndrome coronavirus-2 (SARS-CoV-2). J Med Virol 92:699-702. https:// doi.org/10.1002/jmv.25915

6. Roberto KT, Espiritu AI, Fernandez MLL, Gutierrez JC (2020) Electroencephalographic findings in COVID-19 patients: a systematic review. Seizure 82:17-22. https://doi.org/10.1016/j. seizure.2020.09.007

7. Desforges M, Le Coupanec A, Dubeau P et al (2019) Human coronaviruses and other respiratory viruses: underestimated opportunistic pathogens of the central nervous system? Viruses 12:14. https://doi.org/10.3390/v12010014

8. Moher D, Liberati A, Tetzlaff J, Altman DG (2009) Preferred Reporting Items for Systematic Reviews and Meta-Analyses: the PRISMA statement. J Clin Epidemiol 62:1006-1012. https://doi. org/10.1016/j.jclinepi.2009.06.005

9. Murad MH, Sultan S, Haffar S, Bazerbachi F (2018) Methodological quality and synthesis of case series and case reports. BMJ Evidence-Based Med 23:60-63. https://doi.org/10. 1136/bmjebm-2017-110853

10. Wells G, Shea B, O'Connell D, Peterson J, Welch V (2011) The Newcastle-Ottawa Scale (NOS) for assessing the quality of casecontrol studies in meta-analyses. Eur J Epidemiol 25:603-605

11. Younger DS (2020) Postmortem neuropathology in Covid-19. Brain Pathol. https://doi.org/10.1111/bpa.12915

12. von Weyhern CH, Kaufmann I, Neff F, Kremer M (2020) Early evidence of pronounced brain involvement in fatal COVID-19 outcomes. Lancet 395:e109. https://doi.org/10.1016/s0140-6736(20) 31282-4

13. Matschke J, Lütgehetmann M, Hagel C, Sperhake JP, Schröder AS, Edler C, Mushumba H, Fitzek A, Allweiss L, Dandri M, Dottermusch M, Heinemann A, Pfefferle S, Schwabenland M, Sumner Magruder D, Bonn S, Prinz M, Gerloff C, Püschel K, Krasemann S, Aepfelbacher M, Glatzel M (2020) Neuropathology of patients with COVID-19 in Germany: a postmortem case series. Lancet Neurol 19:919-929. https://doi.org/10. 1016/s1474-4422(20)30308-2

14. Keller E, Brandi G, Winklhofer S, Imbach LL, Kirschenbaum D, Frontzek K, Steiger P, Dietler S, Haeberlin M, Willms J, Porta F, Waeckerlin A, Huber M, Abela IA, Lutterotti A, Stippich C, Globas C, Varga Z, Jelcic I (2020) Large and small cerebral vessel involvement in severe COVID-19. Stroke 51:3719-3722. https://doi.org/ 10.1161/strokeaha.120.031224

15. Kantonen J, Mahzabin S, Mäyränpää MI, Tynninen O, Paetau A, Andersson N, Sajantila A, Vapalahti O, Carpén O, Kekäläinen E, Kantele A, Myllykangas L (2020) Neuropathologic features of four autopsied COVID-19 patients. Brain Pathol. 30:1012-1016. https:// doi.org/10.1111/bpa.12889

16. Jensen MP, Le Quesne J, Officer-Jones L et al (2020) Neuropathological findings in two patients with fatal COVID-19. Neuropathol Appl Neurobiol. https://doi.org/10.1111/nan.12662

17. Jaunmuktane Z, Mahadeva U, Green A, Sekhawat V, Barrett NA, Childs L, Shankar-Hari M, Thom M, Jäger HR, Brandner S (2020) Microvascular injury and hypoxic damage: emerging neuropathological signatures in COVID-19. Acta Neuropathol 140:397-400. https://doi.org/10.1007/s00401-020-02190-2

18. Fabbri VP, Foschini MP, Lazzarotto T, Gabrielli L, Cenacchi G, Gallo C, Aspide R, Frascaroli G, Cortelli P, Riefolo M, Giannini C, D'Errico A (2020) Brain ischemic injury in COVID-19-infected patients: a series of 10 post-mortem cases. Brain Pathol. https:// doi.org/10.1111/bpa.12901

19. Bradley BT, Maioli H, Johnston R, Chaudhry I, Fink SL, Xu H, Najafian B, Deutsch G, Lacy JM, Williams T, Yarid N, Marshall DA (2020) Histopathology and ultrastructural findings of fatal COVID-19 infections in Washington State: a case series. Lancet 396:320-332 10.1016/s0140-6736(20)31305-2

20. Mukhopadhyay S, Ghosh S, Stroberg E, Duval EJ, Barton LM (2020) COVID-19 autopsies, Oklahoma, USA. Am J Clin Pathol 153:725-733. https://doi.org/10.1093/ajcp/aqaa062

21. Patel HN, Syed A, Lobel JS, Galler R, Georges J, Carmody M, Puumala M (2020) Cerebellar infarction requiring surgical decompression in patient with COVID 19 pathological analysis and brief 
review. Interdiscipl Neurosurg 22:100850. https://doi.org/10.1016/ j.inat.2020.100850

22. Reichard RR, Kashani KB, Boire NA, Constantopoulos E, Guo Y, Lucchinetti CF (2020) Neuropathology of COVID-19: a spectrum of vascular and acute disseminated encephalomyelitis (ADEM)-like pathology. Acta Neuropathologica 140:1-6. https://doi.org/10. 1007/s00401-020-02166-2

23. Conklin J, Frosch MP, Mukerji S et al (2020) Cereberal microvascular injury in severe COVID-19. medRxiv Prepr Serv Heal Sci. https://doi.org/10.1101/2020.07.21.20159376

24. Schurink B, Roos E, Radonic T, Barbe E, Bouman CSC, de Boer HH, de Bree GJ, Bulle EB, Aronica EM, Florquin S, Fronczek J, Heunks LMA, de Jong MD, Guo L, du Long R, Lutter R, Molenaar PCG, Neefjes-Borst EA, Niessen HWM, van Noesel CJM, Roelofs JJTH, Snijder EJ, Soer EC, Verheij J, Vlaar APJ, Vos W, van der Wel NN, van der Wal AC, van der Valk P, Bugiani M (2020) Viral presence and immunopathology in patients with lethal COVID-19: a prospective autopsy cohort study. Lancet Microbe 1:e290-e299. https://doi.org/10.1016/s2666-5247(20)30144-0

25. Al-Sarraj S, Troakes C, Hanley B et al (2020) Invited review: the spectrum of neuropathology in COVID-19. Neuropathol Appl Neurobiol. https://doi.org/10.1111/nan.12667

26. Solomon IH, Normandin E, Bhattacharyya S, Mukerji SS, Keller K, Ali AS, Adams G, Hornick JL, Padera RF Jr, Sabeti P (2020) Neuropathological features of Covid-19. N Engl J Med 383:989992. https://doi.org/10.1056/NEJMc2019373

27. Schaller T, Hirschbühl K, Burkhardt K, Braun G, Trepel M, Märkl B, Claus R (2020) Postmortem examination of patients with COVID-19. JAMA 323:2518-2520. https://doi.org/10.1001/jama. 2020.8907

28. Kim MG, Stein AA, Overby P, Kleinman G, Nuoman R, Gulko E, al-Mufti F, Pisapia JM, Muh CR (2021) Fatal cerebral edema in a child with COVID-19. Pediatr Neurol 114:77-78. https://doi.org/ 10.1016/j.pediatrneurol.2020.10.005

29. van den Enden AJM, van Gils L, Labout JAM, van der Jagt M, Moudrous W (2020) Fulminant cerebral edema as a lethal manifestation of COVID-19. Radiol Case Reports 15:1705-1708. https:// doi.org/10.1016/j.rader.2020.06.053

30. Helms J, Kremer S, Merdji H, Clere-Jehl R, Schenck M, Kummerlen C, Collange O, Boulay C, Fafi-Kremer S, Ohana M, Anheim M, Meziani F (2020) Neurologic features in severe SARSCoV-2 infection. N Engl J Med 382:2268-2270. https://doi.org/10. 1056/NEJMc2008597

31. Fayed I, Pivazyan G, Conte AG, Chang J, Mai JC (2020) Intracranial hemorrhage in critically ill patients hospitalized for COVID-19. J Clin Neurosci 81:192-195. https://doi.org/10.1016/ j.jocn.2020.08.026

32. Varga Z, Flammer AJ, Steiger P, Haberecker M, Andermatt R, Zinkernagel AS, Mehra MR, Schuepbach RA, Ruschitzka F, Moch H (2020) Endothelial cell infection and endotheliitis in COVID-19. Lancet 395:1417-1418. https://doi.org/10.1016/ s0140-6736(20)30937-5

33. Sharifi-Razavi A, Karimi N, Rouhani N (2020) COVID-19 and intracerebral haemorrhage: causative or coincidental? New Microbes New Infect 35:100669. https://doi.org/10.1016/j.nmni. 2020.100669

34. Melmed KR, Cao M, Dogra S, Zhang R, Yaghi S, Lewis A, Jain R, Bilaloglu S, Chen J, Czeisler BM, Raz E, Lord A, Berger JS, Frontera JA (2020) Risk factors for intracerebral hemorrhage in patients with COVID-19. J Thromb Thrombolysis. https://doi.org/ 10.1007/s11239-020-02288-0

35. Ellul MA, Benjamin L, Singh B, Lant S, Michael BD, Easton A, Kneen R, Defres S, Sejvar J, Solomon T (2020) Neurological associations of COVID-19. Lancet Neurol 19:767-783. https://doi.org/ 10.1016/s1474-4422(20)30221-0
36. Moriguchi T, Harii N, Goto J, Harada D, Sugawara H, Takamino J, Ueno M, Sakata H, Kondo K, Myose N, Nakao A, Takeda M, Haro H, Inoue O, Suzuki-Inoue K, Kubokawa K, Ogihara S, Sasaki T, Kinouchi H, Kojin H, Ito M, Onishi H, Shimizu T, Sasaki Y, Enomoto N, Ishihara H, Furuya S, Yamamoto T, Shimada S (2020) A first case of meningitis/encephalitis associated with SARS-Coronavirus-2. Int J Infect Dis 94:55-58. https://doi.org/ 10.1016/j.ijid.2020.03.062

37. Rifino N, Censori B, Agazzi E, Alimonti D, Bonito V, Camera G, Conti MZ, Foresti C, Frigeni B, Gerevini S, Grimoldi M, la Gioia S, Partziguian T, Quadri S, Riva R, Servalli MC, Sgarzi M, Storti B, Vedovello M, Venturelli E, Viganò M, Callegaro A, Arosio M, Sessa M (2020) Neurologic manifestations in 1760 COVID-19 patients admitted to Papa Giovanni XXIII Hospital, Bergamo. Italy. J Neurol. https://doi.org/10.1007/s00415-020-10251-5

38. Freire-Álvarez E, Guillén L, Lambert K, Baidez A, García-Quesada M, Andreo M, Alom J, Masiá M, Gutiérrez F (2020) COVID-19associated encephalitis successfully treated with combination therapy. Clin Infect Pract. 7-8:100053. https://doi.org/10.1016/j.clinpr. 2020.100053

39. Haider A, Siddiqa A, Ali N, Dhallu M (2020) COVID-19 and the brain: acute encephalitis as a clinical manifestation. Cureus. 2: e10784. https://doi.org/10.7759/cureus. 10784

40. Varatharaj A, Thomas N, Ellul MA, Davies NWS, Pollak TA, Tenorio EL, Sultan M, Easton A, Breen G, Zandi M, Coles JP, Manji H, al-Shahi Salman R, Menon DK, Nicholson TR, Benjamin LA, Carson A, Smith C, Turner MR, Solomon T, Kneen R, Pett SL, Galea I, Thomas RH, Michael BD, Allen C, Archibald N, Arkell J, Arthur-Farraj P, Baker M, Ball H, BradleyBarker V, Brown Z, Bruno S, Carey L, Carswell C, Chakrabarti A, Choulerton J, Daher M, Davies R, di Marco Barros R, Dima S, Dunley R, Dutta D, Ellis R, Everitt A, Fady J, Fearon P, Fisniku L, Gbinigie I, Gemski A, Gillies E, Gkrania-Klotsas E, Grigg J, Hamdalla H, Hubbett J, Hunter N, Huys AC, Ihmoda I, Ispoglou S, Jha A, Joussi R, Kalladka D, Khalifeh H, Kooij S, Kumar G, Kyaw S, Li L, Littleton E, Macleod M, Macleod MJ, Madigan B, Mahadasa V, Manoharan M, Marigold R, Marks I, Matthews P, Mccormick M, Mcinnes C, Metastasio A, Milburn-McNulty P, Mitchell C, Mitchell D, Morgans C, Morris H, Morrow J, Mubarak Mohamed A, Mulvenna P, Murphy L, Namushi R, Newman E, Phillips W, Pinto A, Price DA, Proschel H, Quinn T, Ramsey D, Roffe C, Ross Russell A, Samarasekera N, Sawcer S, Sayed W, Sekaran L, Serra-Mestres J, Snowdon V, Strike G, Sun J, Tang C, Vrana M, Wade R, Wharton C, Wiblin L, Boubriak I, Herman K, Plant G (2020) Neurological and neuropsychiatric complications of COVID-19 in 153 patients: a UK-wide surveillance study. Lancet Psychiatry 7:875-882. https://doi.org/10.1016/ s2215-0366(20)30287-x

41. Gu J, Gong E, Zhang B, Zheng J, Gao Z, Zhong Y, Zou W, Zhan J, Wang S, Xie Z, Zhuang H, Wu B, Zhong H, Shao H, Fang W, Gao D, Pei F, Li X, He Z, Xu D, Shi X, Anderson VM, Leong ASY (2005) Multiple organ infection and the pathogenesis of SARS. J Exp Med 202:415-424. https://doi.org/10.1084/jem.20050828

42. Xu J, Zhong S, Liu J, Li L, Li Y, Wu X, Li Z, Deng P, Zhang J, Zhong N, Ding Y, Jiang Y (2005) Detection of severe acute respiratory syndrome coronavirus in the brain: potential role of the chemokine mig in pathogenesis. Clin Infect Dis 41:1089-1096. https:// doi.org/10.1086/444461

43. Arabi YM, Harthi A, Hussein J, Bouchama A, Johani S, Hajeer AH, Saeed BT, Wahbi A, Saedy A, AlDabbagh T, Okaili R, Sadat M, Balkhy H (2015) Severe neurologic syndrome associated with Middle East respiratory syndrome corona virus (MERS-CoV). Infection 43:495-501. https://doi.org/10.1007/s15010-015-0720-y

44. Williams OH, Mohideen S, Sen A, Martinovic O, Hart J, Brex PA, Sztriha LK (2020) Multiple internal border zone infarcts in a patient 
with COVID-19 and CADASIL. J Neurol Sci 416:116980. https:// doi.org/10.1016/j.jns.2020.116980

45. Beyrouti R, Adams ME, Benjamin L, Cohen H, Farmer SF, Goh YY, Humphries F, Jäger HR, Losseff NA, Perry RJ, Shah S, Simister RJ, Turner D, Chandratheva A, Werring DJ (2020) Characteristics of ischaemic stroke associated with COVID-19. J Neurol Neurosurg Psychiatry 91:889-891. https://doi.org/10.1136/ jnnp-2020-323586

46. Oxley TJ, Mocco J, Majidi S, Kellner CP, Shoirah H, Singh IP, de Leacy RA, Shigematsu T, Ladner TR, Yaeger KA, Skliut M, Weinberger J, Dangayach NS, Bederson JB, Tuhrim S, Fifi JT (2020) Large-vessel stroke as a presenting feature of Covid-19 in the young. N Engl J Med 382:e60. https://doi.org/10.1056/ NEJMc2009787

47. Nadim MK, Forni LG, Mehta RL, Connor MJ Jr, Liu KD, Ostermann M, Rimmelé T, Zarbock A, Bell S, Bihorac A, Cantaluppi V, Hoste E, Husain-Syed F, Germain MJ, Goldstein SL, Gupta S, Joannidis M, Kashani K, Koyner JL, Legrand M, Lumlertgul N, Mohan S, Pannu N, Peng Z, Perez-Fernandez XL, Pickkers P, Prowle J, Reis T, Srisawat N, Tolwani A, Vijayan A, Villa G, Yang L, Ronco C, Kellum JA (2020) COVID-19associated acute kidney injury: consensus report of the 25th Acute Disease Quality Initiative (ADQI) Workgroup. Nat Rev Nephrol 16:747-764. https://doi.org/10.1038/s41581-020-00356-5

48. Ammar MA, Sacha GL, Welch SC, Bass SN, Kane-Gill SL, Duggal A, Ammar AA (2020) Sedation, analgesia, and paralysis in COVID-19 patients in the setting of drug shortages. J Intensive Care Med. 36:157-174. https://doi.org/10.1177/ 0885066620951426

49. Serebrovska ZO, Chong EY, Serebrovska TV, Tumanovska LV, Xi L (2020) Hypoxia, HIF-1 $\alpha$, and COVID-19: from pathogenic factors to potential therapeutic targets. Acta Pharmacol Sin 41:15391546. https://doi.org/10.1038/s41401-020-00554-8

50. Shirota Y, Hirase Y, Suda T, Miyazawa M, Hodo Y, Wakabayashi $\mathrm{T}$ (2020) More than half of hypoxemia cases occurred during the recovery period after completion of esophagogastroduodenoscopy with planned moderate sedation. Sci Rep 10:4312. https://doi.org/ 10.1038/s41598-020-61120-0

51. Qadeer MA, Lopez AR, Dumot JA, Vargo JJ (2011) Hypoxemia during moderate sedation for gastrointestinal endoscopy: causes and associations. Digestion 84:37-45. https://doi.org/10.1159/ 000321621

52. Ferrari M, Quaresima V (2020) Hypoxemia in COVID-19: cerebral oximetry should be explored as a warning indicator for mechanically ventilated adults with COVID-19. Respir Res 21:261. https:// doi.org/10.1186/s12931-020-01530-w

53. Pezzini A, Padovani A (2020) Lifting the mask on neurological manifestations of COVID-19. Nat Rev Neurol 16:636-644. https://doi.org/10.1038/s41582-020-0398-3

54. Guadarrama-Ortiz P, Choreño-Parra JA, Sánchez-Martínez CM, Pacheco-Sánchez FJ, Rodríguez-Nava AI, García-Quintero G (2020) Neurological aspects of SARS-CoV-2 infection: mechanisms and manifestations. Front Neurol 11:1039. https://doi.org/ 10.3389/fneur.2020.01039

55. Iadecola C, Anrather J, Kamel H (2020) Effects of COVID-19 on the nervous system. Cell 183:16-27.e11. https://doi.org/10.1016/j. cell.2020.08.028

56. Mehta S, Bhandari S, Mehta S (2020) Brain autopsies in fatal COVID-19 and postulated pathophysiology: more puzzling than a Rubik's cube. J Clin Pathol.:jclinpath-2020-206967. https://doi. org/10.1136/jclinpath-2020-206967

57. Jarrahi A, Ahluwalia M, Khodadadi H, da Silva Lopes Salles E, Kolhe R, Hess DC, Vale F, Kumar M, Baban B, Vaibhav K, Dhandapani KM (2020) Neurological consequences of COVID19: what have we learned and where do we go from here? J Neuroinflammation 17:286. https://doi.org/10.1186/s12974-02001957-4

Publisher's note Springer Nature remains neutral with regard to jurisdictional claims in published maps and institutional affiliations. 